\title{
Overview of ergonomics built environment
}

\author{
Ana Paula Lima Costa ${ }^{\mathrm{a}}$, Fábio Campos ${ }^{\mathrm{b}}$ and Vilma Villarouco ${ }^{\mathrm{c}}$ \\ ${ }^{a, b, c}$ Federal University of Pernambuco, Professor Moraes Rego Avenue, 1235 - Cidade Universitária. Recife, \\ Pernambuco, Brazil.
}

\begin{abstract}
This article provides an overview of academic research in the scientific discipline of ergonomics in the context of the built environment, from data collected from journals, conferences and research groups whose focus is the theme of the Ergonomics of Built Environment. Starting from the context of the Ergonomics of Built Environment, it identifies the broadcast media who publish work in this area and its scientific production, seeking to recover from the first published papers to the production of the most recent scientific journals and conferences to be launched 2010. From this mapping, we identified the major outstanding and open issues in these studies, outlining the state of the art Ergonomics Built Environment, in order to inform those interested and intend to develop scientific research in this field.
\end{abstract}

Keywords: architecture; environmental comfort; human factors

\section{Introduction}

The search for the definition of a field of study if is not well planned can be infinite. In an attempt to offer an unprecedented look about it, it runs the risk of making a very specific approach, of limited application. Back a broader view on the matter is a prerequisite for launching valid questions for those interested in the scientific field, awakening interest in the scientific community.

In the intention to map out the playing field that is the ergonomics of the built environment was conducted this survey of the scientific evidence which may lead to support future studies in this field of work.

\section{Method}

It was necessary contextualization of ergonomics as a scientific discipline, reaching the field of study, scientific production, seeking to recover from the earliest published works, which would set guidelines the beginning of scientific interest in this area, to the productions most recent showing the current concern of researchers.

Starting from the context of the ergonomics of the built environment, it identifies the broadcast media which publishes work in this area and its scientific
* production, seeking to recover from the first published papers to the production of the most recent scientific meetings and scientific journals and conferences. From this mapping, we identified the most outstanding issues and the open ones in these studies, outlining the state of the art of ergonomics of the built environment, in order to inform those who are interested and intend to develop scientific research in this field.

The scientific community is influenced by the impact factor of the bases (journals and conferences) in which the work is published. Previously, the assessment criteria for academic excellence was the amount of published works, the tendency today is to enhance the quality of publications, verified by the level of interest of researchers for a job, obtained through the number of citations of research, in other references authors in their work. This assessment is known as the Impact Factor, which determines the amount of times a publication is cited in a certain period of time divided by the number of articles published in the same period.

Since the intent of this research is to map the academic and scientific production was carried out research on two bases: publishing journals that have a high impact factor and most significant conferences in the area of ergonomics.

\footnotetext{
* Corresponding authors: aplimacosta@gmail.com fc2005@gmail.comvillarouco@hotmail.com,
} 


\section{Determines ergonomics}

Ergonomics or human factor is a recent seach field of just over 50 years. Derived from the greek ergon (work) and nomos (laws) to denote the science of work. According to the IEA - International Ergonomics Association, ergonomics is a system-oriented discipline that extends to all aspects of human activity, promoting a holistic approach in which considerations of physical, cognitive, social, organizational, environmental and other relevant factors are taken into account [9].

According to IEA [9], within the discipline there are areas of expertise that represent deeper competencies in specific human attributes or characteristics of human interaction. Thus, the physical ergonomics is directed to areas whose characteristics are related to physical activity, cognitive ergonomics is concerned with mental processes and how they affect interactions among humans and other elements of a system, and the organizational ergonomics is concerned with the optimization sociotechnical systems, including their organizational structures, policies and processes.

Classifying ergonomics according to their field, it will act in products, production systems or control, production, information, technology transfer and the built environment.

\subsection{Ergonomics of the built environment}

Defining the ergonomics and the application of knowledge of human characteristics for the design of systems, Parsons [12] shows that, within a system, people operate within an environment, so the ergonomics of the environment is concerned with how people interact with the environment in terms of ergonomics.

The ergonomics of the physical environment is understood as the evaluation of the environment through an physical measurements of the environment, the subjective responses of people. According to IEA [9], Ergonomics of the physical environment involves issues related to thermal comfort, the signs of danger to public areas and methods, assessment of speech communication and audio signals to the consumer.

Ergonomics has, in its scope, a variety of methodologies that address the built environment, which contribute to the ergonomic study. According to Ribeiro [14], environmental ergonomics is concerned with man's relationship to the task you perform and the means used, the called system human-machinetask. With a systematic focus on the human part of the system, ergonomics seeks to adapt the means of the task for the welfare of man. For environmental ergonomics, the means are the built environment. Researches on environmental perception are located on the concerns of research within the scope of cognition and are based on cognitive maps and in research techniques, such as systematic observations of behavior at the study and questionnaires, which allow morphological analysis from the mental maps.

Villarouco [16] states that there are many variables involved in identifying the suitability of the built environment, which makes the task of measuring this adequacy is overly complex, especially when we see a focus on ergonomics. This statement is echoed when one considers that the issue addresses concerns regarding the various areas of knowledge, as "The ergonomics of the environment goes beyond purely architectural issues, focusing on its position in the adaptability of space and compliance tasks and activities that it will develop" [17].

Thus, the ergonomics of the built environment does not study the environment by considering only the physical variables without considering the question of orientability, accessibility, furniture design, optimization, graphic design or lighting.

\section{Results}

Concern about the built environment from the perspective of ergonomics can be seen in 1970 when Wools and Canter [18] describes the development of three semantic scales to assess the physical environment, generated from the reactions of the drawings, suggesting a hypothesis about the adequacy of the physical environment for an activity. In 1972, Brookes [5] conducts a case study on the effects of changes in the office environment in which attitudes and perceptions of employees of a company that has adopted an employment office wide were recorded using an instrument of scale semantics, with the intention of apply these data in a significant reformulation.

Among congress and journals directed to publish articles on ergonomics, were checked to have areas of interest related to the ergonomics of the built environment, from the search tools provided by them.

Within the content of scientific papers identified, it was observed that the following issues were raised: 


\subsection{Papers published in journals}

The following journals available online were surveyed:

\subsubsection{Applied ergonomics: human factors in technology and society}

"Applied Ergonomics" is a journal aimed at achieving ergonomists interested in applying ergonomics / human factors in design, planning and management of technical systems and social and leisure, including the areas of office applications, industry, consumer products, information technology and military design. It has subscribers in over 50 countries and welcomes original contributions on the practical applications of ergonomic design and research.[3]

In it files we found the following issues related to built environment:

- Ergonomic thermal Revision, 2010

- Method interdisciplinary assessment, 2009

- Development of tools and their use, 2009

- Investigation of lighting conditions, 2009

- Case Study of thermal conditions, 2008

- Psychological effects on the circulation of air, 2008

- Case study on ergonomic office users, 2008

- Case study on the effects of lighting, temperature, color and subjective mood in an office, 2008

- Impacts on the psychosocial work environment among employees, 2008

- Results in terms of ergonomic comfort and productivity, 2006

- Study on furniture: aspects of attitudes, respect and satisfaction, 2006

- Review of principles, methods and models of environmental ergonomics, 2000

- Relationship between furniture and visual comfort, 1999-1990

- Study on the noise in the environment, 19801989

- Ergonomics and lighting, 1980-1989

- Evaluation of thermal stress in the workplace with individual micro climate conditions unequal, 1980-1989

- Security for the visually handicapped, 19801989

- Study on the noise in the environment, 19701979

- Study of behavior in an office environment, 1970-1979
- Studies office in widescreen: reactions, functionality, lighting comfort, employee attitudes, noise, 1970-1979

- Study on the climate in the environment, 19701979

\subsubsection{Ergonomics}

"Ergonomics" is the official journal of the Institute for Ergonomics and Human Factors. It is an international, multidisciplinary, dedicated to research on all aspects of the interactions of humans and their work and leisure, including psychological, physiological, and anatomical aspects of engineering design, and a publication to disseminate high-quality research and papers reporting research results from cognate disciplines that contribute to the understanding of systems [7].

It features articles on the built environment since 1966:

- "Evaluation of the Built Environment." An inaugural lecture delivered at University College, London, 1966.

- Analysis of dynamic work environments, 1991

- Evaluation of the workplace, 1992

- Effects of office for health and performance, 2009.

\subsubsection{Indoor and built environment}

The "Journal of Indoor and Built Environment" published by the International Society of the Built Environment (ISBE) publishes reports on the quality of indoor and built and how they may affect the health, performance, efficiency and comfort of people. Topics include urban infrastructure, building design and materials used for laboratory studies, including simulations of animals and in vitro effects.[10]

The subjects of the articles of 2009 related to the ergonomics of the built environment were:

- Measurement of heat conduction in buildings

- Value of environmental quality with the occupant satisfaction and performance certificates of buildings

- Measure the airflow around the human body refrigerated

- Ratings of visual comfort

- Environmental control to reduce diseases

- Indoor environmental quality of school

- Ratings thermal, thermal efficiency, thermal environment for the elderly and classrooms, and thermal comfort environment of air conditioning in offices, radiation in buildings 
- Reviews on the air: movement, dispersion and change of air, ventilation, airflow, ventilation system, heat transfer by air

\subsubsection{Ambiente construído}

Edited by the Technology Association of the Built Environment (ANTAC, in portuguese), for the areas of civil engineering, architecture and urban design, Ambiente Construído (Built Environment, in english) is a scientific journal covering the whole area of technology of the built environment.[2]

It has an online version, the magazine ANTAC online, in which the subjects of published articles related to the built environment are related to:

- Design process and the perception of users

- Case study of acoustic comfort in office spaces

- Thermal comfort and condition of the architectural-landscape

- Sound insulation of walls

- Improvement climatization pain

- The concept of environmental comfort in the performance of the work environment

- Performance benchmarking office building

\subsection{Papers presented in congress}

The production of scientific research is also influenced by the observed direction of the papers presented at conferences that operate in the area. However, it was found in research that, even bearing the title "Environmental Ergonomics Congress' has some application to the area of ergonomics built environment, such as the "International Conference on Environmental Ergonomics", held in Boston, USA, whose publications are related to the area of psychology and physiology.

The conference identified that publish articles in the area of application of ergonomics built environment were:

\subsubsection{IEA 2009}

In 2009 came the 17th tri-annual world congress of the International Ergonomics Association (IEA), a company that brings together 42 countries, involving more than 20,000 members.[9]

In the intention to introduce the perception and future directions of ergonomics for science in its last congress in 2009, the world congress of the International Ergonomics Association (IEA) presented as general papers in their technical sections:

- Research concepts and methods to improve the ergonomics of construction projects,
- A multidisciplinary approach including architecture, ergonomics and psychology.

- Adopting the perspective of human ergonomics to understand work activities and their demands for architectural programming.

- Presentation of human-environmental features that should be considered in the architectural design to base the design process.

- Analysis of ergonomic office environments;

- Assessment of the level of satisfaction felt by employees;

- The interference environment of the classroom in the teaching and learning of deaf.

- Presentation of a methodology for ergonomic intervention in a built environment

\subsubsection{HFES 2009 annual meeting}

Proceedings of the Human Factors and Ergonomics Society is a company that has more than 400 presentations reflecting the diversity of the topic in human factors / ergonomics. [8]

In 2009, in U.S.A. was the 53rd annual meeting of the Proceedings of the Human Factors and Ergonomics Society. The environmental design was present with the following technical sessions:

- Considerations on aging and disability evaluation of approaches used to accommodate people with disabilities in housing, observation of the conceptual framework of data collection and programming facilities, inclusive design of educational spaces and analysis of local needs for the elderly.

- Considerations office environment and student affairs, in which studies on the effects of colored lighting and environmental conditions of offices.

- A collection of articles, where he presented a work on the model of integration of assistive technology for people with disabilities, simulations of visual impairment to detect problems, control of environmental conditions using ventilation systems and personal research on the preferences of the interfaces to the smart home American and Korean users.

\subsubsection{ABERGO 2010}

The ABERGO is a nonprofit association whose purpose is to study, practice and dissemination of the interactions of people and technology, organization and environment, considering their needs, abilities and limitations. It is affiliated with the IEA. 
The 16th Brazilian Congress of Ergonomics promoted by the Brazilian ergonomics association were technical sessions devoted to the topic "ergonomics and built environment and urban", whose themes were discussions ergonomic methodologies and assessment for the built environment, perception of environmental variables and case studies of ergonomic evaluation of built environments.[1]

\subsubsection{ErgoDesign 2010}

The first ErgoDesign was held in Switzerland in 1984 under the initiative of Prof. Etienne Grandjean, and since 2001 has been performed in Brazil, as a single event with the theme ergodesign products, information, built environment and human-computer interaction. Its target groups are professionals of architecture, design, engineering, ergonomics, physiotherapy and occupational therapy, occupational physical education, computer science, medicine, nursing, psychology, visual communication, ergonomics, software, computer professionals.[6]

In the 10th ErgoDesign in 2010, the interest of the congress was focused on items that contribute to research and work of the target audience of the congress, and in the area of environmental ergonomics, is particularly interested in the issues of:

- Use of the internal space or urban, based on the concepts of territoriality, public and private space;

- Interaction between individuals with the space, the architectural barriers, bookmarks and spatial cognitive maps;

- Navigation and movement in architectural space and organization and accessibility of urban areas for better use of space in the built environment and quality of life of city residents.

\subsubsection{ENCAC-ELACAC 2009}

The Brazilian National Meeting of the Built Environment Comfort - ENCAC is a meeting of the Brazilian National Association of Technology Built Environment, the ANTAC, technical and scientific association, multidisciplinary, bringing together professionals, researchers and technical organ of the areas of housing, construction and technology architecture [20].

In X ENCAC, conducted in 2009 were three technical sessions devoted to the topic "ergonomics and post-occupancy evaluation in environmental comfort" in which we have some contributions of ergonomic concepts of activity and situation of collective work in the design of spaces. References to ergo- nomic building environmental were found in 17 articles, with issues relating to:

- Implementation of universal design / accessibility

- Use of tactile maps

- Evaluation of the built environment

- Reviews post-occupation

- Evaluation of environmental comfort

- Ergonomic evaluation of the built environment

- Focus of the built environment from the ergonomics of the built environment

- Measurements of environmental variables

- Analyze dimensional

- Visual ergonomics.

\subsubsection{ENEAC 2009}

The ENEAC, National Meeting of the Built Environment Ergonomics in Brazil is a specific event in the area of ergonomics Built Environment. It is a event created by ABERGO working group "Ergonomics of the Built Environment"[19].

The II ENEAC, held in 2009, presented the following thematic articles:

- Reviews ergonomic of work environments

- Perceptions about the needs of users

- Use of scaling and anthropometry

- Use of ergonomic methods

- Ratings ergonomic criteria

- Use of post-occupation

\section{Contents of papers}

\subsection{Questions presented}

Within the content of scientific papers identified, it was observed that the following issues were raised:

\subsubsection{Papers published in journals}

In the journal "Applied Ergonomics" notes that studies on noise, climate and behavior in an office environment panoramic were recurring themes in the 70 's. In the $80 \mathrm{~s}$, was studied the noise in the environment and evaluation of thermal stress in the workplace. In the $90 \mathrm{~s}$, the theme of the articles published in the journal was a review of methods of ergonomics and environmental relationship between furniture and visual comfort.

From the year 2000, we as subjects of articles: the presentation of results in terms of ergonomic comfort and productivity study on furniture (2006), case study of thermal conditions, lighting, color and sub- 
jective mood of psychological effects on air circulation, impacts on the psychosocial work environment between workers and users on ergonomic office (year 2008). Articles published in 2009 refer to valuation, using tools and research of lighting and editing that will be published in 2010 has theme related to ergonomics heat.

In the magazine "Ergonomics" articles about the built environment assessments were published in the 90s. Articles published in 2009 reported the effects of office for health and performance.

In 2009 the journal "Indoor and Built Environment" had the theme of the articles about the evaluation of visual and thermal comfort, environmental quality and environmental control.

In the journal "Ambiente Construído" articles are available about the design process and the perception of users, the concept of comfort and environmental case study of acoustic and thermal comfort.

\subsubsection{Papers presented in congress}

In the intention to introduce the perception and future directions of ergonomics for science in its last congress in 2009, the world congress of the International Ergonomics Association (IEA) beyond have been presented case studies of ergonomic evaluation of built environments, the interdisciplinary environment of ergonomics built was discussed at various levels in a multidisciplinary approach that extends the ergonomics to understand the human activities of work, aiming to build the process of design environments; also was presented a specific methodology for ergonomic intervention in the built environment.

In the 53th annual meeting of Proceedings of the Human Factors and Ergonomics Society(HFES), design was present in environmental considerations on aging and disability by addressing the accommodation, understanding and assistive technology for people with disabilities and considerations for the office environment, studying the effects of lighting, ventilation and environmental conditions.

In the Brazilians congress who have technical sessions on ergonomics of the built environment, the topics of the papers presented may be condensed into:

- The 10th ErgoDesign, held in 2010 the articles were about the ergonomic analysis of work environment and contributions of methods for ergonomic evaluation of built environments.

- In ANTAC congress held in 2009 had case studies of evaluation of the built environment.
- In the annals of ENCAC-ELACAC occurred in 2009 , included work on the analysis of the built environment, the dimensional analysis, and evaluation of environmental comfort.

- The II ENEAC in 2009 submitted articles and thematic assessments in environments and ergonomic criteria, perceptions of user needs, use of scaling environments, anthropometric and ergonomic methods.

- The 16th ABERGO 2010, submitted articles on discussions ergonomic methodologies and case studies of ergonomic evaluation of built environments.

\subsection{Open issues}

It is observed that in the journals are work on evaluations of the built environment and verification of environmental factors, such as studies on temperature, noise, etc., pointing out that in the 90's studies on the environments of the open plan was a popular option theme. However, the application of ergonomics in the built environment as a whole, mean, in all its aspects, it is a topic still unexplored.

Although architecture is one of the pillars of the discipline of ergonomics built environment, architecture targeted journals are not found in publications which issue is ergonomics, found only in journals for ergonomic studies. This reflects the low penetration of discipline ergonomics program in the grid architecture, reflecting the recent inclusion of this discipline in modern life.

In general, the inclusion of articles on ergonomics of the built environment is a theme in recent meetings of the built environment and the congress of ergonomics in the total amount presented at conferences.

Among the papers presented, there are a majority of the articles on case studies of ergonomic assessments of the built environment, both from the standpoint of the global environment and analysis of indices of environmental factors. Note also that the search for a method of environmental analysis is a recurrent theme in several editions of scientific congresses and meetings, resulting from the phase of discovery and recognition that this aspect of ergonomics is going through. 


\section{Discussion}

As Parsons [12] provides in its 2000 study, that there are few studies in the ergonomics of the built environment is a clear demonstration that there are few researchers and institutions that consider the human response over the environment as a whole, assuming that while the environments are evaluated from the components separately, the building occupants are exposed to these components in an integrated manner. As reported in their study, "there is much knowledge and application of new approaches will allow the knowledge of the ergonomics of the environment is an important and essential to the research of ergonomics." [12]

As noted in the most academically respected the media, the scientific field of the ergonomics of the built environment has not been disclosed in its area of operation and application, producing the built environment. It is for developers of major scientific mission to fill this gap by implementing this new vision of human occupation on the cornerstones of knowledge already firmly established, contributing to a better relationship between man and his environment, avoiding suffering and damage.

Maybe the problem traced by Mülfarth in 2007 in his article "A realidade do arquiteto e o ensino da ergonomia: proposta do departamento de tecnologia da FAU-USP" (The reality of the architect and the teaching of ergonomics: a proposal from the technology department at FAU-USP) [11], which shows the proposal for applied education at FAU / USP with the discipline of ergonomics, tell us that the path would be to include the discipline of ergonomics integrated in the curriculum from course architecture as a means of awakening the professionals of the importance of these methodological principles in the building.

\section{References}

[1] ABERGO $2010-16^{\circ}$ Congresso Brasileiro de ErgonomiaPrograma Oficial de Anais de resumos. Rio de Janeiro, RJ 2010. CD-ROM

[2] Ambiente Construído. www.antac.org.br/ ambienteconstruido. Accessed in 10/12/2009
[3] Applied Ergonomics. www.elsevier.com/wps/find/jour naldescription.cws home/30389/description\#description. Accessed in $10 / 31 / 2009$

[4] Architectural Design. www3.interscience.wiley.com/ journal $/ 109924136 /$ home?CRETRY $=1 \&$ SRETRY $=0$. Accessed in $10 / 24 / 2009$

[5] Brookes, Malcolm J. Office Landscape: Does it Work? In: Applied Ergonomics, Volume 3, Issue 4, December 1972, Pages 224-236.

[6] $10^{\circ}$ ERGODESIGN 2010. $10^{\circ}$ Congresso Internacional de Ergonomia e Usabilidade de Interfaces Humano-tecnologiae. Anais de Resumos. Rio de Janeiro, RJ. 2010. CD-ROM

[7] Ergonomics. www.tandf.co.uk/journals/terg. Accessed $10 / 25 / 2009$

[8] HFES 2009. www.hfes.org/web/HFESMeetings/09annual meeting .html. Accessed in 11/21/2009

[9] IEA, The International Ergonomics Association. www.iea.cc/. Accessed 10/25/2009

[10]Indoor and Built Environment. http://ibe.sagepub.com. Accessed 11/06/2009

[11]Mulfarth. Roberta C. Kronka. A realidade do arquiteto e o ensino da ergonomia: proposta do departamento de tecnologia da FAU-USP. In anais do IX Encontro Nacional e V Latino Americano de Conforto do Ambiente Construído, 2007. CDROM

[12] Parsons, K. C. Environmental ergonomics: a review of principles, methods and models. In Applied Ergonomics, Volume 31, Issue 6, December 2000, Pages 581-594.

[13] Qualis.http://qualis.capes.gov.br/webqualis/ConsultaPeriodico s.faces. Accessed 09/23/2009

[14]Ribeiro, Lúcia Gomes. Ergonomia no ambiente construído um estudo de caso em aeroportos. Dissertação (mestrado), Departamento de Artes e Design, PUC, Rio de Janeiro, 2004.

[15]17th World Congress on Ergonomics, IEA 2009. www.iea2009.org/index.htm.

[16] Villarouco, Vilma. An ergonomic look at the work environment. In: Anais do 17th World Congress on Ergonomics, Beijing, China, 2009

[17] Villarouco, V.; Santos, N. Ergonomia do Ambiente Construído. In: Anais do II ERGODESIGN - II Congresso Internacional de Ergonomia e Usabilidade de Interfaces Humano-Tecnologia: Produtos, Programas, Informação, Ambiente Construído, Rio de Janeiro, 2002.

[18] Wools, Roger; Canter, David. The effect of the meaning of buildings on behaviour. In: Applied Ergonomics, Volume 1, Issue 3, June 1970, Pages 144-150, 1970

[19]II ENEAC: II Encontro Nacional de Ergonomia do Ambiente Construído e III Seminário Brasileiro de Acessibilidade Integral. Programa Oficial e Anais de Resumos, Recife, PE; 2009. CD-ROM

[20]X ENCAC- VI ELACAC 2009. Encontro Nacional de Conforto no Ambiente Construído. Caderno de resumos. Editado por Enedir Ghisi, Virginia Maria Dantas de Araújo, Aldomar Pedrini; Natal, RN, 2009. CD-ROM 